\title{
Pregnancy and immune thrombocytopenia: New trends
}

To the Editor,

I've read the article written by Kalaycı et al. (1) with interest. I'd like to emphasize a few points. The term "idiopathic thrombocytopenic purpura" has been abandoned and replaced with "immune thrombocytopenia" following the Vicenza Concensus of 2009. This was as a result of new understanding concerning the pathophysiology of the disease, although the abbreviation "Immune thrombocytopenic purpura (ITP)" remained the same. Also from the diagnosis, up to the first three months, between 3-12 months and after 12 months is now defined as acute, persistent and chronic ITP respectively. The term "primary ITP" should be used unless another condition, such as autoimmune disorders, co-exist. To diagnose ITP, the thrombocyte count should be below $100 \times 10^{9} / \mathrm{L}$ (2). ITP is diagnosed in between one and 10 of every 10,000 pregnancies and $30 \%$ of cases need therapy. If no other hemostatic abnormality exists, thrombocyte count at delivery should be between 75 to $80 \times 10^{9} / \mathrm{L}$ and this view is supported by most guidelines. The "safe" platelet level to prevent postpartum bleeding has been suggested to be $50 \times 10^{9} / \mathrm{L}$ in one study similar to yours (3). The American Society of Hematology and International Working group guidelines support intravenous immunoglobulin or corticosteroids as the first line treatment, and they seem to be equally potent in enhancing thrombocyte counts. Intravenous immunoglobulin can achieve a fast but temporary increase in trombocyte counts and is a very useful option for conditions such as delivery or bleeding. Both agents can be given in combination refractory to single agents alone (4). Thrombocyte concentrates should not be used unless there's a potential life threating bleed. Fetal malformation risk restricts the choice for second-line treatment. Azathioprine may be considered to spare steroids. Anti-RhD immunoglobulin, cyclosporine, and rituximab could be good alternatives, as this has been previously reported although they are not routinely used (4). In an experimental study, it was reported that recombinant human thrombopoietin may be a safe and effective option for the treatment of pregnant ITP patients. Recombinant human thrombopoietin (rhTPO) treatment in ITP at pregnancy is reported in murine models. Significant higher platelet counts were noted in rhTPO-treated groups with no teratogenic effects; supporting that it could be a safe and effective option for refractory cases (5). Although all there is much data, the pregnancy-ITP relationship remains to be illuminated with further prospective studies.

\section{İran Yavaşoğlu, Atakan Turgutkaya}

\section{Department of Hematology, Adnan Menderes University Medical Faculty, Aydın, Turkey}

\section{References}

1. Kalaycı H, Doğan Durdağ G, Baran ŞY, Yüksel Şimşek S, Alemdaroğlu S, Özdoğan S, et al. Pregnancy of patients with idiopathic thrombocytopenic purpura: maternal and neonatal outcomes. J Turk Ger Gynecol Assoc 2020; 21: 97-101.

2. Rodeghiero F, Stasi R, Gernsheimer T, Michel M, Provan D, Arnold $\mathrm{DM}$, et al. Standardization of terminology, definitions and outcome criteria in immune thrombocytopenic purpura of adults and children: Report from an international working group. Blood 2009; 113: 2386-93.

3. Gilmore KS, McLintock C. Maternal and fetal outcomes of primary immune thrombocytopenia during pregnancy: A retrospective study. Obstet Med 2018; 11: 12-6.

4. Provan D, Arnold DM, Bussel JB, Chong BH, Cooper N, Gernsheimer $\mathrm{T}$, et al; Updated international consensus report on the investigation and management of primary immune thrombocytopenia. Blood Adv 2019; 3: 3780-817.

5. Liu Y, Wang R, Han P, Zhao Y, Li G, Nie M, et al. Effect of recombinant human thrombopoietin on immune thrombocytopenia in pregnancy in a murine model. Int Immunopharmacol 2019; 67: 287-93.

Received: 16 August, 2019 Accepted: 09 November, 2019

Address for Correspondence: Atakan Turgutkaya 


\section{Author's Response}

Dear Editor,

Thank you for precious evaluation and suggestions. The terms and abbreviations which we preferred are consistent with the references included in our manuscript. However, this is a kind reminder of the changes in terms, as well as of some innovations in management. We certainly will consider these comments.

Yours sincerely,

Hakan Kalaycı, Gülşen Doğan Durdağ, Şafak Yılmaz Baran, Seda Yüksel Şimşek, Songül Alemdaroğlu, Serdinç Özdoğan, Esra Bulgan Kılıçdağ

Department of Obstetrics and Gynecology, Başkent University Faculty of Medicine, Adana Application and Research Hospital, Adana, Turkey 